\title{
CORRECTION
}

\section{Correction to: The Performance Analysis of Robust Local Mean Mode Decomposition Method for Forecasting of Hydrological Time Series}

\author{
Levent Latifoğlu' ${ }^{1}$ \\ Published online: 17 February 2022 \\ (c) Shiraz University 2022

\section{Correction to: \\ Iranian Journal of Science and Technology, Transactions of Civil Engineering} \\ https://doi.org/10.1007/s40996-021-00809-2
}

In this article the caption to Fig 2 was incorrectly published as 


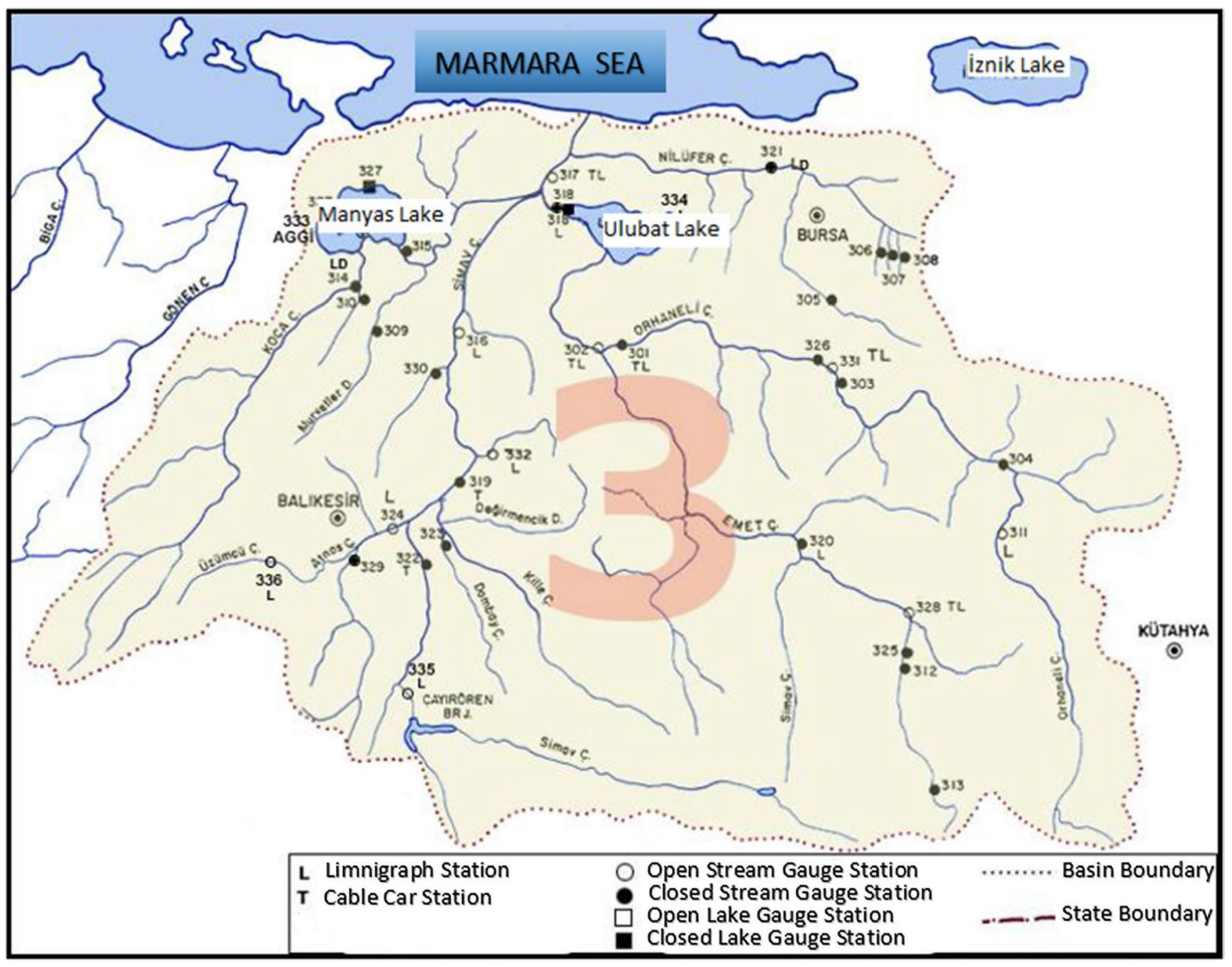

Fig. 2 Basin of Kocadere in Turkey (Smith 2005)

It should read as 


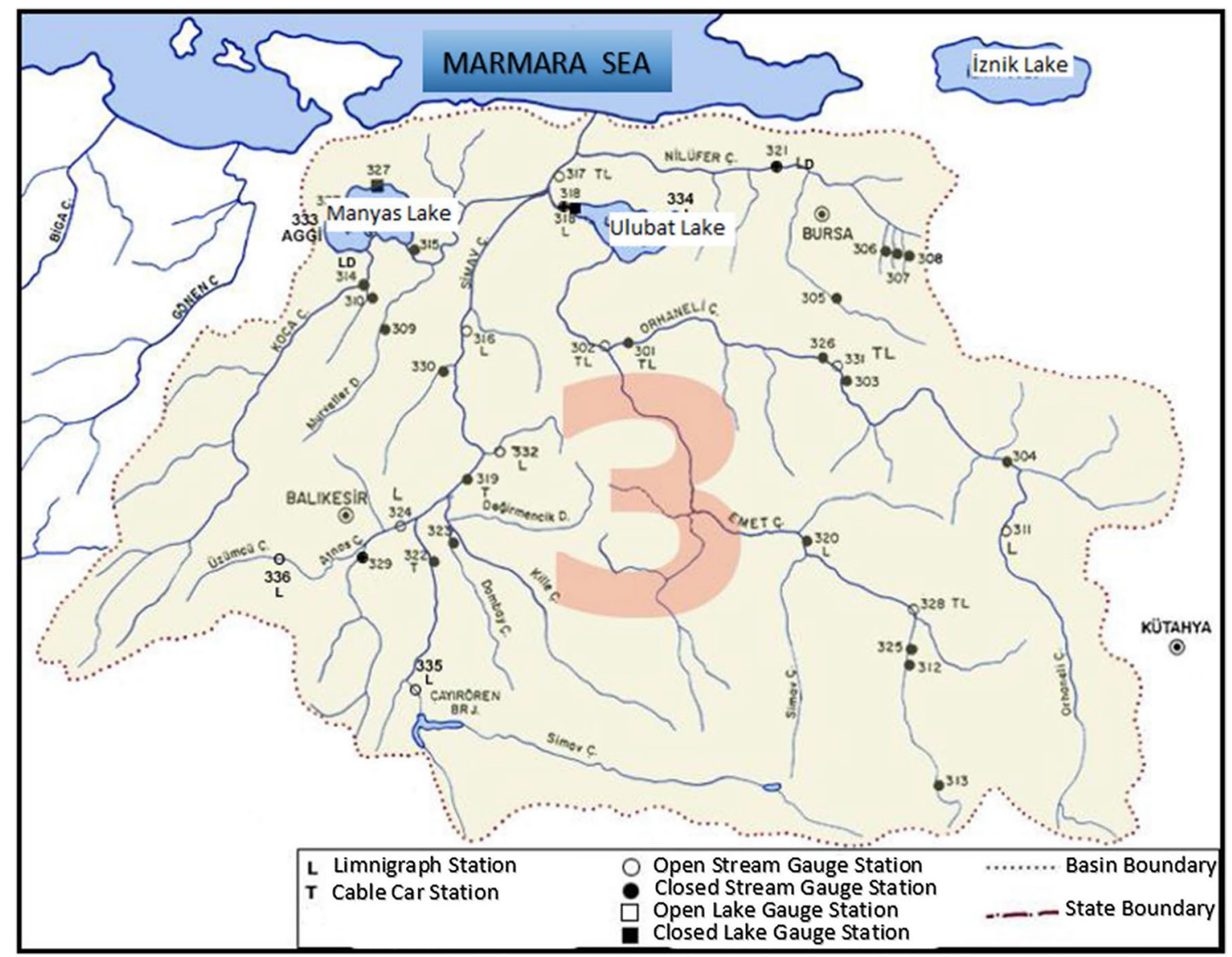

Fig. 2 Basin of Kocadere in Turkey (www.dsi.gov.tr/faali yetler/akim-gozlem-yilliklari, (accession date February, 2020) 